\title{
FODMAP urriko dieta eta haien erabilgarritasuna hesteko gaixotasunen maneiuan
}

\author{
(Low FODMAP diet and its usefulness in the management \\ of intestinal diseases)
}

\author{
Gesala Perez-Junkera, Arrate Lasa*, Jonatan Miranda, Virginia Navarro, \\ Edurne Simón, Idoia Larretxi, Olaia Martinez, Marian Bustamante, \\ Itziar Txurruka, Maialen Vazquez-Polo
}

GLUTEN3S ikerketa taldea, Nutrizio eta Bromatologia Saila, Farmazia Fakultatea

\begin{abstract}
LABURPENA: FODMAPak, modu naturalean esnekietan eta landare jatorriko zenbait elikagaitan aurki daitezkeen konposatuak, zenbait heste-gaixotasunetako sintomekin erlazionatu dira. Kate laburreko karbohidrato hartzigarri hauek zuntzaren antzeko efektuak eragiten dituzte, ur-atxikipena eragiten dute eta koloneko mikrobiotak hartzitzen dituzte, kate laburreko gantz azidoak eta gasak sortuz. Azken urteetan egin diren ikerketetan ikusi da FODMAP-kontsumoak beherakoa eta flatulentzia moduko sintomak eragiten dituela heste-funtzioaren aztoratzea duten gaixotasunetan, heste narritakorraren sindromean, hesteetako hanturazko gaixotasunean eta zeliakian esaterako. Horregatik, FODMAP urriko dieta eraginkorra dela ikusi da gaixotasun horien maneiuan, baina dietaren ezarpena zaila da. FODMAPen iturri diren elikagai asko murriztearen ondorioz, dieta desorekatu eta gabezia nutrizionalak ager daitezke, eta beraz, dietaren maneiu egokirako dietista-nutrizionista baten kontrola ezinbestekoa da. Nahiz eta dieta epe laburrean heste-sintomak murrizteko eraginkorra izan, epe luzera dituen ondorioak jakiteko ikerketa gehiagoren beharra dago, dieta oso murriztailea izan baitaiteke.
\end{abstract}

HITZ GAKOAK: Fermentable Oligosaccharides, Disaccharides, Monosaccharides and Polyols (FODMAP), dieta, elikagaiak, heste-sintomak, heste narritakorraren sindromea (HNS), hesteetako gaixotasun inflamatorioa (HGI), zeliakia, glutenarekiko sentikortasun ez-zeliakoa (GSEZ), esklerosi sistemikoa (ES), fibromialgia.

ABSTRACT: FODMAPs, subtances that can be found naturally in a wide variety of foods such as dairy products and certain plant origin foods, have been associated with symptoms of certain intestinal diseases. These short-chain fermentable carbohydrates show fiber-like effects, such as water retention and microbes' fermentation in colon, producing short-chain fatty acids and gases. Latest research studies in this field have shown that consumption of FODMAP causes symptoms of diarrhea and flatulence in intestinal disorders, such as Irritable Bowel Syndrome, Inflammatory Bowel Disease and Celiac Disease. A low FODMAP diet has shown to be effective in the management of these diseases but its implementation it is not easy. The reduction of foods rich in FODMAPs, results in dietary imbalances and deficiencies, so that, the supervision of a Dietitian-Nutritionist is necessary for a correct dietary management. Although it is an effective diet reducing bowel symptoms in short-term, long-term effects need to be more deeply analyzed because it can be a very restrictive diet.

KEYWORDS: Fermentable Oligosaccharides, Disaccharides, Monosaccharides and Polyols (FODMAP), diet, food, gastrointestinal symptoms, Irritable Bowel Syndrome (IBS), Inflammatory Bowel Disease (IBD), Celiac Disease, Non-Celiac Gluten Sensibility, Systemic Sclerosis (SS), Fibromyalgia.

* Harremanetan jartzeko / Corresponding author: Arrate Lasa. GLUTEN3S ikerketa taldea, Nutrizio eta Bromatologia Saila, Farmazia Fakultatea, Unibertsitate Pasealekua, 7 (01006 Vitoria-Gasteiz). - arrate.lasa@ehu.eus - https://orcid.org/00000003-2399-4979

Nola aipatu / How to cite: Perez-Junkera, Gesala; Lasa, Arrate; Miranda, Jonatan; Navarro, Virginia; Simón, Edurne; Larretxi, Idoia; Martinez, Olaia; Bustamante, Marian; Txurruka, Itziar; Vazquez-Polo, Maialen (2020). «FODMAP urriko dieta eta haien erabilgarritasuna hesteko gaixotasunen maneiuan»; Ekaia, 38, 2020, 155-182. (https://doi.org/10.1387/ekaia.21650).

Jasoa: 14 apirila, 2020; Onartua: 04 maiatza, 2020.

ISSN 0214-9001 - eISSN 2444-3255 / (c) 2020 UPV/EHU

(c) () () Obra hau Creative 


\section{SARRERA}

\subsection{Zer dira FODMAPak?}

FODMAP kate motzeko eta hartzigarriak diren karbohidrato eta poliolen taldea izendatzeko erabilitzen den ingelesezko akronimoa da, «Fermentable Oligosaccharides, Disaccharides, Monosaccharides and Polyols» izenaren siglak biltzen dituena. Karbohidrato talde honen barruan azpitalde ugari daude eta bakoitzean molekula desberdinak sailkatzen dira [1,2] (1. taula). Oro har, esnekietan eta landare-jatorriko zenbait elikagaitan era naturalean aurki daitezkeen substantziak dira, hala nola fruta, barazki, lekale, zereal eta eratorrietan, baita ohiko dietan erabiltzen diren gozogarrietan ere. FODMAP azpitalde bakoitzak berezkoak diren xurgapen- eta hidrolisi-ezaugarriak erakusten baditu ere, orokorrean, FODMAP guztiek hiru ezaugarri funtzional partekatzen dituzte: heste mehean haien xurgapen-maila baxua da, molekula txiki eta osmotikoki aktiboak dira eta hesteko bakterioek azkar hartzitzen dituzte [3]. Hori dela eta, heste-mailan zenbait efektu desiragaitz izan ditzaketela ikusi da eta azken urteotan ga-

1. taula. FODMAP azpitaldeak: molekulen sailkapena eta haien hesteko garraiosistema [1, 2, 7-9].

\begin{tabular}{|c|c|c|}
\hline FODMAP azpitaldea & Molekula mota & Hesteko garraio-sistema \\
\hline \multirow{4}{*}{ Olisakaridoak } & $\begin{array}{l}\text { FOS (fruktooligosakaridoak edo } \\
\text { fruktanoak): } \\
\text { Sakarosa molekula bat fruktosa } \\
\text { batera edo gehiagotara lotuta } \beta \\
\text { (2-1) loturaren bitartez. }\end{array}$ & \multirow{2}{*}{$\begin{array}{l}\text { Heste meheak ez duenez molekula hauen arteko } \\
\beta \text { lotura apurtzeko hidrolasarik, ezin dira hestean } \\
\text { liseritu, heste-epitelioan zehar garraiatu, ezta } \\
\text { xurgatu ere. Hori dela eta, heste lodira heltzen } \\
\text { dira eta hango mikrobiotari esker hartzitzen dira. } \\
\text { Molekula horien \% } 90 \text { baino gehiago hartzitzen } \\
\text { da heste lodian. }\end{array}$} \\
\hline & $\begin{array}{l}\text { GOS (galaktooligosakaridoak edo } \\
\text { galaktanoak): } \\
\text { Laktosa molekula bat galaktosa } \\
\text { molekula bat, bi, hiru edo lauri lo- } \\
\text { tuta } \beta \text { loturen bitartez. }\end{array}$ & \\
\hline & $\begin{array}{l}\text { Maltooligosakaridoak (maltodex- } \\
\text { trina): } \\
\text { glukosaren polimeroak, almidoia- } \\
\text { ren hidrolisitik lortuak; } \alpha \text { (1-4) lo- } \\
\text { tura bidez. }\end{array}$ & \multirow{2}{*}{$\begin{array}{l}\text { Heste mehearen eskuila-ertzeko glukosidasa dei- } \\
\text { turiko entzimek eta beste disakaridasa batzuek } \\
\text { (laktasa eta sakarasa) karbohidrato hauek mo- } \\
\text { nosakaridotan banatzen dituzte, glukosatan ale- } \\
\text { gia. Glukosa garraio aktiboz xurgatzen da hes- } \\
\text { tean. Zenbait heste-gaixotasunetan heste-biloak } \\
\text { kaltetuta daude, eta entzima hauen funtziona- } \\
\text { litatea murriztua dago. Ondorioz, karbohidrato } \\
\text { hauek ez dira digeritzen ezta xurgatzen; heste } \\
\text { lodiraino heltzen dira, eta han bakterioek hartzi- } \\
\text { tzen dituzte. }\end{array}$} \\
\hline & $\begin{array}{l}\text { Isomaltooligoskaridoak: } \\
\text { glukosak beste monosakarido ba- } \\
\text { tzuekin osatzen dituen polime- } \\
\text { roak; } \alpha(1-4) \text { lotura bidez. }\end{array}$ & \\
\hline
\end{tabular}




\begin{tabular}{|c|c|c|}
\hline FODMAP azpitaldea & Molekula mota & Hesteko garraio-sistema \\
\hline Disakaridoak & $\begin{array}{l}\text { Laktosa (glukosa+galaktosa) eta } \\
\text { maltosa (glukosa+glukosa). } \\
\text { Guztiak } \alpha \text { loturez elkartuak. }\end{array}$ & $\begin{array}{l}\text { Laktosa erraz digeritzen da heste mehean laktasa } \\
\text { entzima funtzionala bada. Hidrolizatzean, aska- } \\
\text { tzen diren glukosa eta galaktosa garraio aktiboz } \\
\text { xurgatzen dira. Laktasa entzimaren faltak edo } \\
\text { funtzionaltasun ezak ez du laktosa hidrolizatzea } \\
\text { ahalbidetuko. Ondorioz, heste lodira garraiatuko } \\
\text { da, eta hango bakterioek hartzituko dute. Talde } \\
\text { etniko eta lurralde desberdinen artean, laktasa- } \\
\text { ren defizientziak prebalentzia aldakorra du: \% } 2 \\
\text { izatetik, adibidez lurralde eskandinaviarretan, } \\
\% 90 \text { izatera, Asiako zenbait lurraldetan. Heste } \\
\text { mehean kokatzen diren eskuila-ertzeko zelule- } \\
\text { tako entzimek, glukosidasa deiturikoek, maltosa } \\
\text { ere deskonposatzen dute, monosakarido-unita- } \\
\text { tetan. Glukosidasak funtzionalak ez direnean, } \\
\text { heste lodiko mikrobiotak hartzitzen du maltosa. }\end{array}$ \\
\hline Monosakaridoak & Fruktosa, glukosa eta galaktosa. & $\begin{array}{l}\text { Hiru monosakarido hauek garraio aktiboz xur- } \\
\text { gatzen dira. Fruktosa heste mehean xurgatzen da } \\
\text { GLUT-2 eta GLUT-5 garraiatzaileen bidez, zei- } \\
\text { nak heste biloen eskuila ertzeko zeluletan aur- } \\
\text { kitzen baitira. GLUT-2 bidezko xurgapena erra- } \\
\text { zago gertatzen da baldin fruktosarekin batera } \\
\text { glukosa ere badago, hau da, biak batera eta kan- } \\
\text { titate antzekoetan agertzen badira. Glukosa baino } \\
\text { kantitate handiagoan agertzen denenan, ordea, } \\
\text { okerrago xurgatzen da fruktosa. Horregatik, eli- } \\
\text { kagaiak «gehiegizko fruktosa» duenean (fruktosa } \\
\text { gehiago glukosa baino), gaizki xurgatzen da, eta, } \\
\text { beraz, FODMAP bat dela jotzen da. Fruktosa ba- } \\
\text { karrik xurgatzeko gaitasun eskasa du biztanleria- } \\
\text { ren \% 30ek, eta, zenbait heste-gaixotasun duten } \\
\text { pertsonetan, are handiagoa da prebalentzia hori. } \\
\text { Bestalde, glukosa eta galaktosa epitelioan barrena } \\
\text { xurgatzen dira eta porta zainari esker garraiatzen } \\
\text { dira gibelera. Kontzentrazio baxuetan, glukosa, } \\
\text { sodioaren mende dagoen garraiatzaile bati es- } \\
\text { ker xurgatzen da. Kontzentrazio altuagoetan, bi- } \\
\text { garren garraiatzaile bat aktibatzen da. Galaktosa } \\
\text { ere, garraiatzaile berak erabiliz xurgatzen da. } \\
\text { Monosakarido horiek xurgatzen ez direnean, } \\
\text { heste lodira iritsiko dira, eta han hartzituko dira. }\end{array}$ \\
\hline Poliolak & $\begin{array}{l}\text { Manitola, sorbitola, xilitola eta } \\
\text { maltitola (manosa, glukosa, xi- } \\
\text { losa eta maltosaren karbonilo tal- } \\
\text { dea alkohol talde batera erreduzi- } \\
\text { tzen denean eratzen dira, hurrenez } \\
\text { hurren). }\end{array}$ & $\begin{array}{l}\text { Manitola eta sorbitola antzeko pisu eta tamaina } \\
\text { molekularra duten sei karbonoko poliolezko iso- } \\
\text { meroak dira. Hidrolixo talde baten orientazioan } \\
\text { desberdintzen dira soilik. Partzialki xurgatzen } \\
\text { dira heste meheko epitelioan zehar difusio pa- } \\
\text { siboz. Polidextrosek eta isomaltasek ere, elika- } \\
\text { gaietan erabiltzen diren gehiagarriak direnek, } \\
\text { antzeko jarrera dute. } \\
\text { Xurgatzen ez diren poliolak, heste lodira ailega- } \\
\text { tzean, hartzitu egiten dira. }\end{array}$ \\
\hline
\end{tabular}


G. Perez-Junkera, A. Lasa, J. Miranda, V. Navarro, E. Simón, I. Larretxi, O. Martinez, M. Bustamante, I. Txurruka, M. Vazquez-Polo

rrantzi handia ematen ari zaio FODMAP-kontsumoa murrizteak osasunean izan dezakeen eragina aztertzeari. Nabarmentzekoa da, adibidez, hesteko aztoratze funtzionalak dituzten pazienteen artean gertatzen dena, FODMAPz urria den dieta egitean urdail-hesteetako sintomak murrizten dituela ikusi baita [4-6].

Azken urteotan «FODMAP berriak» izena eman zaien beste molekula batzuk ere pasatu dira dietako substantzia horien taldea osatzera. Molekula horien artean, jarraian zehazten direnak dira ezagunenak:

- Pasiboki xurgatutako monosakaridoak, hala nola xilosa eta arabinosa. Xilosa pentosa bat da, urdaileko xurgapen-probetan pasiboki eta astiro-astiro xurgatzen dena. Xurgatzen ez dena heste lodian hartzitzen da. Elikagaien xilosa-edukia ez dago ondo definituta, baina jakina da barazki eta frutetan agertzen dela. Arabinosa elikagaietan gehigarri gisa erabiltzen da eta aipatutako FODMAPen eragin antzekoak ditu (xurgapen geldoa eta ez guztizkoa; ondorioz, heste lodira heltzean hartzigarria da).

- Digeriezinak diren beste oligosakarido batzuk: Heste mehean hidrolizatzen ez diren dietako beste oligosakarido batzuk ere existitzen dira, hala nola isomalto-oligosakaridoak (sojaren eratorrietan) eta xilo-oligosakaridoak (bambu ernamuinean eta zenbait fruta eta barazkitan). Hala ere, eguneroko dietan sarri kontsumitzen ez diren elikagaiak dira, eta ez dago haien edukiaren balioa adierazten duen zerrenda kuantitatiborik. Oro har, ez dira sintoma eragile garrantzitsurik izango, baina herrialde konkretu batzuetan, Japonian adibidez, konposatu hauen elikagai-iturriak gehiago kontsumitzen direnez, osasunean eragina ote duten ala ez jakitea interesgarria litzateke.

- Laktulosa: Laktosaren isomero bat da; sintetikoki esnea berotuz lortzen da eta medikuntzan laxante bezala erabiltzen da. Hala ere, entzefalopatia hepatikoa duten pazienteetan, laktulosak jasaten duen hartziduraren ondorioz, koloneko pH-a murrizteko eta era honetan nitrogeno molekulen absortzioa gutxitzeko ere erabiltzen da.

- Inulina: Fruktosa molekula ugari (20-60 bitarte) elkartzean sortzen den oligofruktanoa da. Industrian jogurretan gehitu ohi da elikagai prebiotikoak egiteko. Kate luzeeneko inulinek heste mehean efektu osmotikoa dutela ikusi da [4].

\section{ZER ERAGIN DUTE FODMAP-ek OSASUNEAN?}

FODMAPak osatzen dituzten zenbait molekula (GOS eta FOSak kasu) zuntz dietetikoaren barnean ere sailkatzen dira, eta beraz, zuntzak osasunean izan ditzakeen efektuak dituzte. Uraren atxikipena eragiten dute; horrela, digestio-hodiko ur edukia handitzen da. Bestalde, hesteetako mi- 
krobiotak hartzitu egiten ditu. Hartzidura areagotzeak eta likidoen kargak heste mehe distalean eta kolon proximalean lumenaren distentsioa eragiten dute. Horrek, erraietako hipersentsibilitatearekin batera, asetze-sentsazioa eta tripako mina eragiten du.

Kontrara, jakina da halako konposatuen hartziduraren ondorioz kate motzeko gantz azidoak gehiegi ekoizten direla, hala nola propionatoa, butiratoa eta azetatoa, efektu onuragarri asko erakusten dituztenak. Butiratoa, zehazki, koloneko epitelioarentzako energia-iturririk garrantzitsuena da, eta urdaileko epitelioaren mantenurako onuragarria da. Gainera, propionatoak eta azetatoak efektu erregulatzaileak dituzte, glukoneogenesia edota kolesterol-sintesia murritz baitezakete. Hala ere, kate motzeko gantz azido hauek toxikoak izan daitezke epitelioarentzat, kontzentrazio altuetan baldin badaude: urdail-mukosatik 5-hidroxitriptamina askatzea estimulatzen dute; anplitude handiko koloneko kontrakzioen sorreran laguntzen dute, eta, era horretan, heste-igarotzea azkartzen da [2]. Erantzunok heste-jarduera aldarazten dute, hala nola beherakoa, idorreria, edo biak batera izatea.



1. irudia. FODMAPetan aberatsak diren eikagaiak hartu ostean, heste mehetik heste lodira garraiatu bitartean azaltzen diren ondoezak. The Pipetten Blogeko irudi moldatua [10]. 


\section{ZEIN ELIKAGAITAN DAUDE FODMAPak?}

Gorago aipatu bezala, FODMAPak dietako elikagai-iturri desberdinetan (frutak, barazkiak, zerealak, lekaleak, fruitu lehorrak, esnea eta esnekiak...) aurki daitezkeen konposatuak dira. 2. taulan, elikagai talde desberdinetan sailkatzen diren FODMAP-eduki askoko eta -eduki urriko zenbait elikagai agertzen dira. Ikerketa ugari egin dira elikagaiak beren FODMAP-edukiaren arabera banatzeko [11-13], baina, kontrara, gutxi batzuek bakarrik plazaratu dituzte elikagaien FODMAP-eduki zehatzak. Elikagai zehatz baten FODMAP kantitatearen analisia egiteko, elikagai beraren zenbait lagin hartzen dira eta horien nahasketa homogeneo bat prestatzen da. Ondoren, FODMAPak erauzten dira eta kromatografia bidez neurtzen dira [13].

2. taula. Dietako elikagaien sailkapena haien FODMAP-edukiaren arabera. Canicoba et al., 2016 [7] etik moldatutako taula.

\begin{tabular}{c|c|c|c}
\hline $\begin{array}{c}\text { Elikagai } \\
\text { taldea }\end{array}$ & $\begin{array}{c}\text { FODMAP-eduki altua } \\
\text { duten elikagaiak* }\end{array}$ & $\begin{array}{c}\text { FODMAP-eduki urria } \\
\text { duten elikagaiak* }\end{array}$ & \multicolumn{1}{c}{$\begin{array}{c}\text { FODMAP nagusiak } \\
\text { elikagai taldean }\end{array}$} \\
\hline Esnekiak & $\begin{array}{c}\text { Esnea (behiarena, ahun- } \\
\text { tzarena, ardiarena), izoz- } \\
\text { kia, gazta bigunak eta } \\
\text { freskoak, jogurta, esne- } \\
\text { krema }\end{array}$ & $\begin{array}{l}\text { Laktosa gabeko esnea, } \\
\text { gazta gogorrak, zenbait } \\
\text { gazta bigun (camem- } \\
\text { bert, cheddar, mozzarela } \\
\text { gaztak - behiarenak- } \\
\text { cottage gazta, ahuntza- } \\
\text { rena) }\end{array}$ & Laktosa \\
\hline Frutak & $\begin{array}{l}\text { Alesagarra, pikua, oka- } \\
\text { rana, udarea, angurria, } \\
\text { mangoa, sagarra, gerezia }\end{array}$ & $\begin{array}{l}\text { Ahabia, anana, platanoa, } \\
\text { mugurdia, kiwia, manda- } \\
\text { rina, marakuia, meloia, } \\
\text { masusta, laranja, pome- } \\
\text { loa }\end{array}$ & $\begin{array}{l}\text { Gehiegizko fruktosa, oli- } \\
\text { gosakaridoak, polialkoho- } \\
\text { lak }\end{array}$ \\
\hline Barazkiak & $\begin{array}{l}\text { Baratxuria, orburua, bro- } \\
\text { kolia, apioa, batata, kuia, } \\
\text { tipula, zainzuriak, azalo- } \\
\text { rea, porrua, erremolatxa, } \\
\text { aza berdea, juka }\end{array}$ & $\begin{array}{l}\text { Zerba, alpalpa, alberji- } \\
\text { nia, ziazerba, mihilua, } \\
\text { uraza, patata, pepinoa, } \\
\text { errefaua, arbia, txinatar } \\
\text { aza, koloredun aza, bru- } \\
\text { selar aza, tomatea, aze- } \\
\text { narioa }\end{array}$ & koholak \\
\hline Fruitu \\
lehorrak
\end{tabular}




\begin{tabular}{|c|c|c|c|}
\hline $\begin{array}{c}\text { Elikagai } \\
\text { taldea }\end{array}$ & $\begin{array}{l}\text { FODMAP-eduki altua } \\
\text { duten elikagaiak* }\end{array}$ & $\begin{array}{l}\text { FODMAP-eduki urria } \\
\text { duten elikagaiak** }\end{array}$ & $\begin{array}{l}\text { FODMAP nagusiak } \\
\text { elikagai taldean }\end{array}$ \\
\hline Zerealak & $\begin{array}{l}\text { Garia, zekalea, garaga- } \\
\text { rra, amarantoa (eta era- } \\
\text { torriak) }\end{array}$ & $\begin{array}{l}\text { Gluten gabeak eta erato- } \\
\text { rriak: artoa, arroza, oloa, } \\
\text { artatxikia, sorgoa, kinoa }\end{array}$ & Oligosakaridoak \\
\hline Lekaleak & $\begin{array}{l}\text { Txitxirioak, dilistak, ba- } \\
\text { barrun gorriak, soja }\end{array}$ & Tofua & Oligosakaridoak \\
\hline Gozoak & $\begin{array}{l}\text { JMAFa (fruktosa askoko } \\
\text { arto-jarabea), eztia eta } \\
\text { - ol amaiera duten goza- } \\
\text { garriak: eritritola (E968), } \\
\text { isomaltosa (E953), lak- } \\
\text { titola (E966), maltitola } \\
\text { (E965), manitola (E421), } \\
\text { sorbitola eta sorbitol-ja- } \\
\text { rabeak (E420) eta xili- } \\
\text { tola (E967) }\end{array}$ & $\begin{array}{l}\text {-ol amaiera gabeko go- } \\
\text { zagarriak: azelsulfamoak } \\
\text { (E950), aspartamoa } \\
\text { (E951), azido ziklami- } \\
\text { koa (E952), sodio-, po- } \\
\text { tasio- eta kaltzio-gatzak, } \\
\text { estebiol-glukosidoak } \\
\text { (E960), neohesperidina } \\
\text { dihidrokalkona (E959), } \\
\text { neotamoa (E961), saka- } \\
\text { rina (E954), aspartamo- } \\
\text { eta azelsulfamo-gatza } \\
\text { (E962), sukralosa (E955) } \\
\text { eta taumatina (E957) }\end{array}$ & $\begin{array}{l}\text { Gehiegizko fruktosa, po- } \\
\text { lialkoholak }\end{array}$ \\
\hline Edariak & $\begin{array}{l}\text { Soja edariak, zuku indus- } \\
\text { trialak, rona, ardo zuria }\end{array}$ & $\begin{array}{l}\text { Arroz-, hur- eta olo-eda- } \\
\text { riak, ahabi-zukua, ga- } \\
\text { ragardoa, ardo beltza, } \\
\text { vodka, whiskya }\end{array}$ & Polialkoholak \\
\hline $\begin{array}{l}\text { Olioak eta } \\
\text { gantzak }\end{array}$ & & $\begin{array}{l}\text { Oliba-olioa, eguzkilore- } \\
\text { olioa, arto-olioa, marga- } \\
\text { rina, gurina }\end{array}$ & \\
\hline
\end{tabular}

* FODMAP-eduki altua duten elikagaiak: gehiegizko fruktosa $0,5 \mathrm{~g} / 100 \mathrm{~g}$ elikagai, $3 \mathrm{~g}$ frukto$\mathrm{sa} / 100 \mathrm{~g}$ elikagai edo $0,2 \mathrm{~g}$ fruktano/100 g elikagai denean, adibidez.

** FODMAP-eduki urria duten elikagaiak: oligosakaridoentzako muga 0,2 g/100 g elikagai baino baxuagoa denean, zerealen eta aleen oligosakaridoak (GOS + fruktano totalak) $0,3 \mathrm{~g} / 100 \mathrm{~g}$ elikagai mugaren azpitik daudenean, eta gehiegizko fruktosa $0,15 \mathrm{~g} / 100 \mathrm{~g}$ elikagai mugaren azpitik dagoenean, adibidez [14].

\section{FODMAP URRIKO DIETA}

FODMAP urriko dieta hesteko patologiak dituzten pazienteetan sintoma desberdinak murrizteko helburuarekin aholkatzen den dieta da, baina ez da, ordea, bizitza osoan zehar egin behar den dieta bat. Aurretiaz aipatu bezala, pertsona bakoitzak erantzun desberdina edukiko du karbohidrato desberdinen aurrean [15], eta kalte egiten duten karbohidratoak zeintzuk diren jakiteko egiten da dietaren ezarpena. Horren arabera, dietatik zein 
G. Perez-Junkera, A. Lasa, J. Miranda, V. Navarro, E. Simón, I. Larretxi, O. Martinez, M. Bustamante, I. Txurruka, M. Vazquez-Polo

elikagai kendu eta zein ez eta zenbat denboraz mantenduko den ere erabakiko da.

Dieta nutrizionalki egokia izatea zaila da, oso murriztailea izan baitaiteke eta gabeziak ekar baititzake. Adibidez, Molina-Infante et al.-ek 2016an egindako ikerketa batean kaltzio-ingesta murrizten zela ikusi zuten, batez ere esne eta esnekien kontsumoa jaisten zelako. Gabezia hau garrantzitsua izan daiteke umeetan, nerabeetan, haurdun edo edoskitzaroan dauden emakumeetan eta emakume postmenopausikoetan. Esnekiak murriztean ondorio larririk ez izateko, kaltziotan aberatsak diren beste elikagai batzuk bilatu behar dira [16]; esaterako, animalia-jatorriko beste elikagai batzuetan ere agertzen da, baina kantitate txikiagoetan: adibidez, mariskoan, hezur eta guzti jaten diren arrainetan eta abarretan. Urak ere badu kaltzioa, batez ere ur gogorrak, baina kaltzio hori ez da oso erabilgarria izaten [17].

Horrez gain, beste FODMAP batzuen ingesta murrizteak, FOS eta GOSena adibidez, zuntzetan aberatsak diren elikagaien kontsumoa murriztea dakar, eta ondorioz, idorreriarekin eta mikrobiota onuragarriaren murrizketarekin erlazionatu da $[2,18]$. Ikerketa batean, HNSa (heste narritakorraren sindromea) zuten pazienteen artean, lau astez FODMAP urriko dieta egin eta gero, lumeneko bifidobakterioak nabarmenki murriztu zirela konturatu ziren, beste bakterio taldeen edo bakterio kopuru totalaren gain eraginik izan gabe [19]. Beste ikerketa batean, hori ere HNSa zuten pazienteen artean egina, gorotzetako bakterioak neurtu ziren [20]. Ikerketa horretan, pertsona talde batek FODMAP urriko dieta egin zuen eta beste talde batek Australian ohikoa den dieta. Interbentzioa hiru astez mantendu ostean, Clostridium coccoides eta Akkerkmansia muciniphila deritzen espezieen murrizketa nabarmena ikusi zen gorotzetan - lehen espeziak burutiratoa sortzen du, eta bigarrena mukosa osasuntsua izatearen erantzule da-. Ruminococcus espeziaren kantitateak, ordea, mukosa kontsumitzen duen bakterio kaltegarriarenak, areagotu egin ziren. Hala ere, bigarren ikerketa horretan ez zen bifidobakterioen murrizketarik ikusi. Efektu horien aurrean, esan beharra dago dieta egokiro ezartzekotan zuntz-ingesta aproposa bermatu beharra dagoela beste elikagai batzuen bitartez; horrela, idorreria edo floraren murrizketa bezalako efektuak saihestuko dira. Dieta honen balizko eragin kaltegarriak ezeztatzeko, FODMAP urriko dietaren izaera murriztaileak elikadura-portaeraren Nahasmenduen garapenean eragina izan dezakeela ikusi da, batez ere komorbilitate psikologikoak dituzten pertsonetan [21].

Efektu desiragaitz horien guztien aurrean, argi dago FODMAP urriko dieta profesionalen laguntzaz egin beharreko dieta dela, baina, errealitatean, pertsona gehienek inolako laguntzarik gabe jartzen dute praktikan. Dietista-nutrizionistaren lana ezinbestekoa da dieta ezartzeko orduan, beharrezkoa baita dietaren helburuak zeintzuk diren ezagutzea: oreka nutri- 
zional eta kaloriko egokia izatea, maiztasun handiko jarraipena egitea, eta dieta elikadura-portaerara eta bizi-estilora moldatzea [2]. FODMAP urriko dieta konplexua da, eta irakasteko eta ikasteko zaila [2]. Gainera, denbora luzean hura mantentzea zail egiten da, eta nahiko garestia da; izan ere, FODMAPz urriak diren alternatibak edo aukerak bilatzea eta erostea garestiagoa izan daiteke [22]. Kontuan izanik sintomen hobekuntza lortzeko dietarekiko atxikipen handia lortzea ezinbestekoa dela [23], beharrezkoa da dieta aukera anitzekoa eta erakargarria izatea.

Dieta nutrizionalki egokia eta orekatua izan dadin eta efektu desiragaitzik sor ez dezan, lehendabizi, beharrezkoa da dietatik kenduko diren elikagaiak nola ordezkatu behar diren jakitea [7, 24]. Horrez gain, dieta hau ez da bat-batean ezartzen edota norberak nahi duen moduan. Pauso batzuei jarraitu beharra dago. Dieta ezarri aurretik, adibidez, lehenik, balorazio nutrizional eta klinikoa egin behar da. Beharrezkoa da elikadura-portaera, bizi-estiloa, jarduera fisikoa, familiako historia klinikoa, alergiak, intolerantziak, medikamentuak eta gorputz-masaren indizea aztertzea. Adibidez, kontsumitutako zuntz-, gantz-, espezia-, alkohol- eta likido-edukiak balioztatu behar dira, gaixotasunaren sintometan eragina izan baitezakete [2]. Ondoren, dieta honek hiru fase biltzen ditu: hasteko, 2-6 astez FODMAP urriko dieta bat ezartzen da; ondoren, berrezarpen-fase batek jarraitzen du, eta, amaitzeko, FODMAP mota ezberdinen ingestaren pertsonalizazioa egiten da [25].

Lehen fasean, FODMAPz urri diren elikagaiak har daitezke, eta FODMAPz aberatsak direnak saihestu behar dira (2. taula). Fasearen helburua dietak efekturik duen jakitea da. Hasierako fasean, bitartean eta amaieran agertzen diren sintomak eskala baten bidez neurtzen dira, FODMAPz urri den dieta zorrotza egitea baliagarria den edo ez ikusteko [26]. FODMAPz urri den dieta eraginkor bat eginez gero, sintomak 3-4 asteren buruan murriztu edo normaldu beharko lirateke.

Murrizketa-fasearen ondoren, ekidin diren elikagaiak berriro hartu beharko dira. Murriztutako elikagai taldeak banaka sartzen dira dietan eta, horrela, sintomen eragile diren elikagai zehatzak zeintzuk diren determinatuko da. Era honetan, elikagai horien edo konposatu dietetiko zehatz batzuen aurrean, pazientearen banakako tolerantzia zein den adieraziko da. Sintomen hobekuntza lortzen duten pazienteei, ez zaie sintoma-eragile diren elikagaiak jaten uzten. Dena den, elikagaien gutxinakako tolerantzia probatzea garrantzitsua da, denbora luzez elikagai batzuen ingesta alferrik murriztu behar ez izateko eta ondorioz urdail-hesteko ekosistema mikrobianoa ez kaltetzeko. Horrela, pertsona hauen bizi kalitatea ez da urrituko [27].

Dieta pertsonalizatzearen fasean, gaizki toleratu diren elikagaiak jateari uzten zaio. Hala ere, dietatik ezabatutako elikagaien tolerantzia berriro pro- 
batzen da, denboran zehar elikagaien tolerantzia alda daitekeelako. Epe luzera, pertsonalizatuta egongo den eta FODMAPz urri baina era berean askotarikoa izango den dieta egingo du pertsonak, jakinik denbora batera alda daitekeela [25]. Aurretiaz azalduriko pauso guztiak erraz ulertzeko, 2. irudian fase bakoitza zertan datzan azaltzen da laburki.

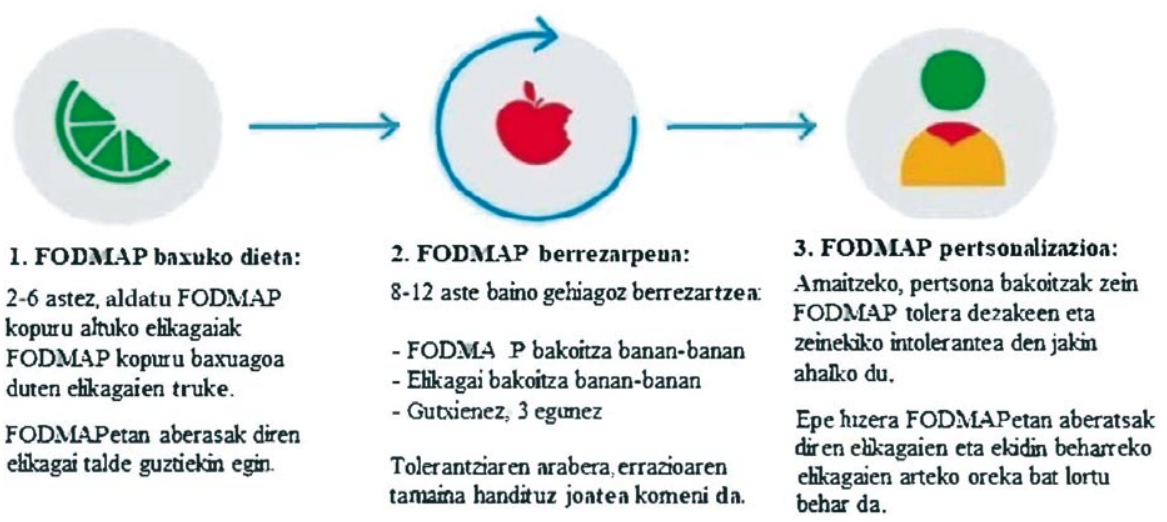

2. irudia. FODMAPz urria den dieta ezartzerakoan jarraitu beharreko faseak. Monash Unibertsitateak argitaratutako irudiaren moldaketa [28].

\section{FODMAP-Z URRIA DEN DIETAREN EFEKTU ONURAGARRIAK HESTEKO HANTURAZKOAN ETA BESTE GAIXOTASUN BATZUETAN}

Jakina da FODMAPek hesteetako hanturazko patologia batzuen sintomatologia areagotu dezaketela [2]. Gaixotasun ikertuenetako bat HNSa izan arren, azken urteetan FODMAP urriko dieta beste hesteko patologia batzuetan ere erabilgarria izan daitekeela ikusi da. Ondorengo lerroetan deskribatzen dira gaixotasun desberdinetan dietaren erabilera demostratzen duten azken 5 urteetako entsegu klinikoak.

\subsection{Heste Narritakorraren Sindromea}

HNSa urdail-hesteko aztoratze funtzionala da. Hestean gertatzen diren aldaketekin erlazionatutako abdomeneko mina eta sabel-hustearen maiztasunaren aldaketak eragiten ditu. Mundu mailan duen prebalentzia \% 11 da eta ohikoagoa da emakumezkoetan eta 50 urte baino gutxiago duten pertsonetan. HNSaren fisiopatologiak hainbat ezaugarri ditu: erraietako hipersentsibilitatea, hesteen motilitate urria edo eza, urdail-hesteko mikrobiotaren disbiosia, burmuin-heste ardatzeko alterazioak eta aldaketa psikosozialak. Jakina da halaber gaixotasun honetan tratamendu farmakologikoa erabil- 
3. taula. FODMAP urriko dietak HNSa duten pazienteetan erakutsi dituen epe motzeko eraginak.

\begin{tabular}{|c|c|c|c|}
\hline Autoreak, urtea & $\begin{array}{l}\text { Lagin tamaina eta } \\
\text { interbentzioaren ezaugarriak }\end{array}$ & $\begin{array}{l}\text { Tratamenduaren } \\
\text { iraupena }\end{array}$ & Emaitzak \\
\hline $\begin{array}{l}\text { Mcintosh et al., } \\
2017[30]\end{array}$ & $\begin{array}{l}\text { Helduak } \\
\text { FUD }(n=19) \\
\text { FAD }(n=18)\end{array}$ & 3 aste & $\begin{array}{l}\text { FODMAP urriko dieta egin zu- } \\
\text { tenek heste eta urdaileko sin- } \\
\text { toma gutxiago eta tripako min } \\
\text { gutxiago izan zuten. }\end{array}$ \\
\hline $\begin{array}{l}\text { Böhn et al., } \\
2015 \text { [31] }\end{array}$ & $\begin{array}{l}\text { Helduak } \\
\text { FUD }(n=33) \\
\text { HSNOG }(n=34)\end{array}$ & 4 aste & $\begin{array}{l}\text { Bi taldeetan berdin murriztu } \\
\text { ziren sintomak. }\end{array}$ \\
\hline $\begin{array}{l}\text { Chumpitazi et al., } \\
2015 \text { [32] }\end{array}$ & $\begin{array}{l}\text { Haurrak } \\
\text { FUD }(n=16) \\
\text { AHGDT }(n=17)\end{array}$ & 48 ordu & $\begin{array}{l}\text { FUDa egin zutenek min abdo- } \\
\text { minal gutxiago eta larritasun } \\
\text { txikiagoa erakutsi zuten. }\end{array}$ \\
\hline $\begin{array}{l}\text { Eswaran et al., } \\
\quad 2016[33]\end{array}$ & $\begin{array}{l}\text { Helduak } \\
\text { FUD }(n=45) \\
\operatorname{mAHGDT}(n=39)\end{array}$ & 4 aste & $\begin{array}{l}\text { Abdomeneko minaren murriz- } \\
\text { keta eta gorotzen trinkotasun } \\
\text { handiagoa FUDa egin zutene- } \\
\text { tan. Sintomen arintzean ezber- } \\
\text { dintasunik ez. }\end{array}$ \\
\hline $\begin{array}{l}\text { Laatikainen et al., } \\
\quad 2016[34]\end{array}$ & $\begin{array}{l}\text { Helduak } \\
\text { Arroz ogia }(n=43) \\
\text { FODMAP urriko } \\
\text { arroz-ogia }(n=44)\end{array}$ & 4 aste & $\begin{array}{l}\text { Abdomeneko min, flatulentzia, } \\
\text { urdail-orro eta heste-karranpa } \\
\text { gutxiago FODMAP urriko } \\
\text { arroz-ogia kontsumitu zuten } \\
\text { pertsonetan. }\end{array}$ \\
\hline $\begin{array}{l}\text { Staudacher et al., } \\
2017[35]\end{array}$ & $\begin{array}{l}\text { Helduak } \\
\text { HSNOG + plazeboa } \\
(\mathrm{n}=27) \\
\text { HSNOG + probiotikoa } \\
(\mathrm{n}=26) \\
\text { FUD + plazeboa }(\mathrm{n}=24) \\
\text { FUD + probiotikoa } \\
(\mathrm{n}=27)\end{array}$ & 4 aste & $\begin{array}{l}\text { Sintoma gutxiago eta bizi ka- } \\
\text { litate hobea FUDa egin zuten } \\
\text { pertsonetan. }\end{array}$ \\
\hline $\begin{array}{l}\text { Hustoft et al., } \\
2017[36]\end{array}$ & $\begin{array}{l}\text { Helduak } \\
\text { FUD eta maltodextrinak } \\
(n=20) \\
\text { FUD eta FOS }(n=20)\end{array}$ & 9 aste & $\begin{array}{l}\text { Sintoma gutxiago eta paziente } \\
\text { gehiago sintoma gutxiagorekin } \\
\text { maltrodextrinarekin suplemen- } \\
\text { tatu zen taldean. }\end{array}$ \\
\hline $\begin{array}{l}\text { Peters } \text { et al., } \\
2015 \text { [37] }\end{array}$ & $\begin{array}{l}\text { Helduak } \\
\text { FUD }(\mathrm{n}=24) \\
\text { Hipnoterapia }(\mathrm{n}=25) \\
\text { FUD + hipnoterapia } \\
(\mathrm{n}=25)\end{array}$ & 6 aste & $\begin{array}{l}\text { Urdail-hesteetako sintomen la- } \\
\text { rritasun baxuagoa FUDan eta } \\
\text { hipnoterapian. Bizi kalitatea } \\
\text { talde guztietan hobetu zen ez- } \\
\text { berdintasun estatistikorik gabe } \\
\text { haien artean. }\end{array}$ \\
\hline
\end{tabular}

Laburdurak: FUD (FODMAP urriko dieta), FAD (FODMAP askoko dieta), HSNOG (HSNa duten pazienteen ohiko gomendiak, AHGDT (Ameriketako haurrentzat gomendantzen den dieta tipikoa), mAHGDT (moldatutako Ameriketako haurrentzat gomendantzen den dieta tipikoa). 
tzea ez dela oso erabilgarria. Hori dela eta, dietoterapia gero eta gehiago erabiltzen da sintomak murrizteko helburuarekin [29]. Proposatzen diren dieten artean, FODMAP urriko dieta nabarmendu da, FODMAPek hestean duten eragina zein zen jakin zenean eta konposatu horien eragite mekanismoa ezagutu zenean, substantzia hauek dietatik kentzeak efektu positiboak izan zitzakeela pentsatu baitzen. Hasiera batean, FODMAP urriko dieta fruktosa eta fruktanoak murriztean bakarrik zentratzen zen. Lehendabiziko dieta hori ezagutza urri batzuetan oinarritu zen, baina ordutik honako ikerketa berriek jakintza gehiago ekarri dute. Modu sistematikoan gaixo guztiei ezartzen zitzaien dieta izatetik era indibidualean ezartzen den dieta izatera igaro da. Orain, HNSa duen norbanako bakoitzak FODMAPekiko duen tolerantzia aztertzen da eta horren araberako dieta ezartzen da [4].

Dieta horren onurak epe motzeko eta epe luzeko interbentzioetan aztertu izan dira honako tauletan ikus daitekeen bezala.

Taulako ondorio gehienek epe laburrean FUDa egin zuten pazienteen artean sintomen eta bizi kalitatearen hobekuntza bat lortu zela adierazten dute.

Lorturiko emaitzek adierazi zuen FUDa epe luzez egiteak sintomen hobekuntza zekarrela eta zenbait kasutan sintomez gain egoera psikologikoarena ere bai. 
4. taula. FODMAP urriko dietak HNSa duten pazienteetan erakutsi dituen epe luzeko eraginak.

\begin{tabular}{|c|c|c|c|}
\hline Autoreak, urtea & $\begin{array}{l}\text { Lagin tamaina eta } \\
\text { interbentzioaren ezaugarriak }\end{array}$ & $\begin{array}{l}\text { Tratamenduaren } \\
\text { iraupena }\end{array}$ & Emaitzak \\
\hline $\begin{array}{l}\text { Peters et al., } \\
2016 \text { [38] }\end{array}$ & $\begin{array}{l}\text { Helduak } \\
\text { FUD + mFUD }(n=24) \\
\text { Hipnoterapia }(n=25) \\
\text { Konbinatua }(n=25) \\
\text { Dietistaren hezkuntza } \\
\text { Nutrizionala FUD jarrai- } \\
\text { tzeko }\end{array}$ & $\begin{array}{l}\text { Tratamendua } \\
6 \text { aste eta } \\
6 \text { hilabetez } \\
\text { jarraipena }\end{array}$ & $\begin{array}{l}\text { FUDa, hipnoterapia eta biak } \\
\text { konbinatuta egin zituzten per- } \\
\text { tsonetan sintomen hobekuntza } \\
\text { orokorra, } 6 \text { hilabetetan man- } \\
\text { tendua. Hipnoterapia kasuan } \\
\text { gehiago, indize psikologikoei } \\
\text { dagokienez (antsietatea eta de- } \\
\text { presioa murriztu ziren). }\end{array}$ \\
\hline $\begin{array}{c}\text { Schumann et al., } \\
2018 \text { [39] }\end{array}$ & $\begin{array}{l}\text { Helduak } \\
12 \text { asteko FUD + mFUD } \\
(\mathrm{n}=29) \\
12 \text { asteko yoga saioak } \\
(\mathrm{n}=30) \\
\text { Dietistaren hezkuntza nu- } \\
\text { trizionala }\end{array}$ & 6 hilabete & $\begin{array}{l}\text { HNSaren Larritasunaren pun- } \\
\text { tuazioa murriztu zen FUD eta } \\
\text { yoga taldeetan, ezberdintasun } \\
\text { estatistiko esanguratsurik gabe } \\
\text { bi taldeen artean. Ospitaleko } \\
\text { antsietatea eta depresioa txi- } \\
\text { kiagoa izan zen yoga taldean. }\end{array}$ \\
\hline $\begin{array}{c}\text { Maagaard et al., } \\
2016[40]\end{array}$ & $\begin{array}{l}\text { Helduak } \\
\text { HNS }(n=31) \\
\text { HGI }(n=49) \\
6-8 \text { asteko FUD + mFUD } \\
(n=180) \\
\text { Dietistaren hezkuntza nu- } \\
\text { trizionala }\end{array}$ & $\begin{array}{l}16 \text { hilabete } \\
\text { batez beste }\end{array}$ & $\begin{array}{l}\text { Sabel-hantura eta abdomeneko } \\
\text { mina murrizteko eragin par- } \\
\text { tziala edo osoa. Heren bat die- } \\
\text { tara atxikitu ziren. FUD ohiko } \\
\text { dieta baino zailagoa eta gares- } \\
\text { tiagoa zela ikusi zen. }\end{array}$ \\
\hline $\begin{array}{c}\text { O'Keeffe } \text { et al., } \\
2018 \text { [22] }\end{array}$ & $\begin{array}{l}\text { Helduak } \\
\text { NICE HSN kriterioak } \\
6 \text { asteko FUD + mFUD } \\
(\mathrm{n}=103) \\
\text { Dietistaren hezkuntza nu- } \\
\text { trizionala }\end{array}$ & 6-18 hilabete & $\begin{array}{l}\text { Abdomeneko mina, sabel-han- } \\
\text { tura eta haize-minak murriztu } \\
\text { ziren epe luzeko jarraipenean. } \\
\text { Sintomen lasaitze asegarria } \\
\text { ikusi zen jarraipenean. mFUDa } \\
\text { ohiko dieta baino garestiagoa } \\
\text { eta zailagoa zela ikusi zen. }\end{array}$ \\
\hline $\begin{array}{c}\text { Harvie et al., } \\
2017 \text { [18] }\end{array}$ & $\begin{array}{l}\text { Helduak } \\
\text { FUD }(n=23) \\
\text { Ohiko dieta }(n=27) \\
\text { MFUD }(n=23) \\
\text { FUD }(n=27) \\
\text { Dietistaren hezkuntza nu- } \\
\text { trizionala }\end{array}$ & 6 hilabete & $\begin{array}{l}\text { HNSren Larritasunaren pun- } \\
\text { tuazioaren murrizketa eta bi- } \\
\text { zi-kalitate hobea FUD taldean } \\
\text { ( } 3 \text { hilabete) eta MFUD taldean } \\
\text { ( } 6 \text { hilabete). }\end{array}$ \\
\hline $\begin{array}{c}\text { Weynants et al., } \\
2019 \text { [41] }\end{array}$ & $\begin{array}{l}\text { Helduak } \\
6-8 \text { asteko FUD + mFUD } \\
(\mathrm{n}=90) \\
\text { Dietistaren hezkuntza nu- } \\
\text { trizionala }\end{array}$ & $49-168$ aste & $\begin{array}{l}\text { Dieta egin zuten pertsonetan } \\
\text { abdomeneko min gutxiago. } \\
\text { Pazienteen } \% 80 \text { dietara atxi- } \\
\text { kitu zen. Bizi-kalitatean ez zen } \\
\text { ezberdintasunik ikusi. }\end{array}$ \\
\hline
\end{tabular}

Laburdurak: FUD (FODMAP urriko dieta), FAD (FODMAP askoko dieta), HNS (heste narritakorraren sindromea), mFUD (moldatutako FUD), HGI (hesteetako gaixotasun inflamantorioa), NICE (National Institute for Health and Clinical Excellence). 
G. Perez-Junkera, A. Lasa, J. Miranda, V. Navarro, E. Simón, I. Larretxi, O. Martinez, M. Bustamante, I. Txurruka, M. Vazquez-Polo

\subsection{Hesteetako Gaixotasun Inflamatorioa}

Hesteetako gaixotasun inflamatorioa (HGI) hesteetako hantura kronikoa eragiten duten gaixotasun errepikakorren taldea da. Geroz eta intzidentzia altuagoa duen mundu mailako arazoa da; haren prebalentzia 1/310 (Chron gaixotasunaren kasuan) eta 1/198 da (kolitis ultzeratiboaren kasuan) [42]. Haren etiologia guztiz ezaguna ez den arren, faktore genetikoek, inguruneak eta hesteko mikroorganismo eta erantzun immunearen arteko interakzio konplexuek parte hartzen dutela uste da [43]. HGIa duten pazienteek sintomen arintze-momentuak izaten dituzte, baina gaixoen proportzio esanguratsu batek sintomak izaten jarraitzen du, hestearen hantura aktiboak eragindakoak ez direnak. Hala ere, sintoma horiek hestearen funtzio-aztoratzearen Rome irizpideak betetzen dituzte [44]. Rome irizpideek urdail-hesteko aztoratze funtzionalen ondorioz sortzen diren sintoma klinikoak sailkatzeko balio dute.

Chron gaixotasuna, kolitis ultzerosoarekin batera, HGIen adibide nagusia da. Gehienbat urdail-heste traktuan eragiten du. Sabel aldeko mina, sukarra, hesteetako buxadura, muki eta/edo odoldun beherakoa ager daitezke seinale kliniko bezala. Estatu Batuetan, adibidez, haren urteroko intzidentzia 3,1-20,2/100.000 biztanle da, eta prebalentzia 201/100.000 biztanle [45]. Espainiako Estatuan, 100.000 biztanleko 6-9 kasu diagnostikatzen dira urtero [46]. Datu epidemiologiko, genetiko eta immunologikoen arabera, faktore anitzeko etiologiadun aztoratze gisa aurkezten da, non batez ere genetikak eta ingurugiroak elkarri eragiten dioten [45].

FUDaren eraginkortasuna agerian geratu zen sintomen larritasuna murriztea lortzean; FADak sintomak handitzen zituen. 
5. taula. FODMAP urriko dietak HGIa duten pazienteetan agertu dituen eraginak.

\begin{tabular}{|c|c|c|c|}
\hline Autoreak, urtea & $\begin{array}{l}\text { Lagin tamaina eta } \\
\text { interbentzioaren } \\
\text { ezaugarriak }\end{array}$ & $\begin{array}{l}\text { Tratamenduaren } \\
\text { iraupena }\end{array}$ & Emaitza \\
\hline $\begin{array}{l}\text { Cox et al., } \\
2017 \text { [44] }\end{array}$ & $\begin{array}{l}\text { Helduak } \\
\text { FODMAPdun edariak } \\
(\mathrm{n}=29)\end{array}$ & 3 egun & $\begin{array}{l}\text { Fruktano-dosi altuek (ez } \\
\text { GOS eta sorbitol) heste-ur- } \\
\text { dail sintomak eragin zituzten } \\
\text { HGI inaktiboan. }\end{array}$ \\
\hline $\begin{array}{l}\text { Prince } \text { et al., } \\
2016 \text { [47] }\end{array}$ & $\begin{array}{l}\text { Helduak } \\
\text { Dieta arrunta }(n=14) \\
\text { FUD }(n=69)\end{array}$ & 6 aste & $\begin{array}{l}\text { FUDak HGIen larritasuna } \\
\text { murrizten zuten pazienteen } \\
\% \text { 78an. Hobekuntzak abdo- } \\
\text { meneko min eta distentsioan, } \\
\text { haize-minetan, korroskade- } \\
\text { tan, goragalean, urdail-azi- } \\
\text { dotasunean, amaitu gabeko } \\
\text { sabel-husteetan eta gorotzen } \\
\text { trinkotasunean egon ziren. }\end{array}$ \\
\hline $\begin{array}{l}\text { Halmos et al., } \\
2016 \text { [48] }\end{array}$ & $\begin{array}{l}\text { Helduak } \\
\text { HGI inaktiboa } \\
\text { FUDa }(\mathrm{n}=4) \\
\text { Australiako ohiko dieta } \\
(\mathrm{n}=4)\end{array}$ & 42 egun & $\begin{array}{l}\text { FUDa erabilgarria izan zen } \\
\text { sintoma funtzionalak mu- } \\
\text { rrizteko Crohn gaixotasuna } \\
\text { zuten pertsonetan. FADak, } \\
\text { aldiz, sintomak handitzen zi- } \\
\text { tuen. }\end{array}$ \\
\hline $\begin{array}{l}\text { Bodini et al., } \\
2019 \text { [49] }\end{array}$ & $\begin{array}{l}\text { Helduak } \\
\text { Ohiko dieta }(n=29) \\
\text { FUDa }(n=26)\end{array}$ & 6 aste & $\begin{array}{l}\text { Bizi-kalitatea hobetu eta epe } \\
\text { motzera FUD segurua zela } \\
\text { ikusi zen. Gorotzetako han- } \\
\text { tura markaitzaileetan hobe- } \\
\text { kuntza ikusten da. }\end{array}$ \\
\hline $\begin{array}{l}\text { Pedersen } \text { et al., } \\
\quad 2017 \text { [50] }\end{array}$ & $\begin{array}{l}\text { Helduak } \\
\text { FUDa }(\mathrm{n}=44) \\
\text { Dieta arrunta }(\mathrm{n}=45)\end{array}$ & 6 aste & $\begin{array}{l}\text { FUDak HNSaren sindromea- } \\
\text { ren antzekoak ziren sintomen } \\
\text { murrizketa eragin zuen. HGI } \\
\text { inaktiboa zuten pertsonen bi- } \\
\text { zi-kalitatea handitu zen. }\end{array}$ \\
\hline $\begin{array}{c}\text { Maagaard et al., } \\
2016[40]\end{array}$ & $\begin{array}{l}\text { Helduak } \\
\mathrm{n}=180\end{array}$ & $\begin{array}{l}16 \text { hilabete } \\
\text { batez beste }\end{array}$ & $\begin{array}{l}\text { FUDa eraginkorra izan zen } \\
\text { hestearen sintomak murriz- } \\
\text { teko. }\end{array}$ \\
\hline
\end{tabular}

Laburdurak: FUD (FODMAP urriko dieta), FAD (FODMAP askoko dieta), HGI (hesteetako gaixotasun inflamatorioa). 
G. Perez-Junkera, A. Lasa, J. Miranda, V. Navarro, E. Simón, I. Larretxi, O. Martinez, M. Bustamante, I. Txurruka, M. Vazquez-Polo

\subsection{Zeliakia eta glutenarekiko sentikortasun ez-zeliakoa}

Zeliakia, definizioz, jatorri autoimmunea duen eta etiologia anitzeko heste-mukosako hantura kronikoa sorrarazten duen gaixotasuna da. Gluten proteinarekiko intolerantzia dutela-eta, genetikoki aurretiaz prestatuta dauden pertsonetan erantzun immunea sorrarazten du zelakiak. Nagusiki heste meheari eragiten dio: bertako bilioen atrofia eta hantura sortzen ditu, eta paretaren iragazkortasuna handitzen du; modu horretan, liseri hodiko sintomak eragiten ditu.. Hala ere, beste organo batzuk kaltetu daitezke eta hestez kanpoko sintomak eragin ditzake, hala nola anemia, dermatitisa, neuropatíak, osteoporosia edo antzutasuna [51, 52]. Hesteko biloak erasanda daudenez, zail egiten da elikagaietatik datozen bitaminak (azido folikoa, besteak beste) eta mineralak (hala nola burdina eta kaltzioa) xurgatzeko gaitasuna mantentzea. Eragozpen hori dela eta, ohikoa da ondorio gisa mikronutrienteen gabeziak pairatzea $[53,54]$. Gaixotasun zeliakoaren prebalentzia mundu mailan \% 1-2 da helduetan [55]. Horrez gain, kontuan hartu behar da diagnostikatu gabeko paziente asintomatikoak ere badaudela. Bestalde, azken urteotan, GSEZa ere deskribatu da; patologia erantzun immunerik gabekoa da, baina zeliakiaren antzeko sintomak ematen ditu. Egoera honen prebalentzia ez da ezaguna, baina gaixotasun zeliakoarena baino handiagoa dela susmatzen da [56].

Orokorrean, GGDa izan zen sintomak murriztearen erantzulea. Horretaz gain, FUDa eramateak ere onurak ekarri zituen sintomen hobetze-mailari zegokionez. 
6. taula. FODMAP urriko dietak gaixotasun zeliakoa duten pazienteetan erakutsi dituen eraginak.

\begin{tabular}{|c|c|c|c|}
\hline Autoreak, urtea & $\begin{array}{l}\text { Laginaren tamaina eta } \\
\text { interbentzioaren ezaugarriak }\end{array}$ & $\begin{array}{l}\text { Tratamenduaren } \\
\text { iraupena }\end{array}$ & Emaitza \\
\hline $\begin{array}{l}\text { Roncoroni et al., } \\
2018 \text { [6] }\end{array}$ & $\begin{array}{l}\text { Helduak } \\
\text { FUDa }(\mathrm{n}=25) \\
\text { Ohiko dieta }(\mathrm{n}=25)\end{array}$ & 3 aste & $\begin{array}{l}\text { FUDaren efektu onuragarriak } \\
\text { urdail-hesteko seinale klini- } \\
\text { koetan. Pertsonen bizi-kalita- } \\
\text { tean eraginik ez. }\end{array}$ \\
\hline $\begin{array}{l}\text { Testa et al., } \\
2018 \text { [57] }\end{array}$ & $\begin{array}{l}\text { Helduak } \\
\text { FUDa }(\mathrm{n}=127)\end{array}$ & 12 aste & $\begin{array}{l}\text { FUD eraginkorra urdail-hes- } \\
\text { teko seinale klinikoak murriz- } \\
\text { ten. Horrela, haien bizi-kalita- } \\
\text { tea eta erlazio sozialak hobetu } \\
\text { ziren. }\end{array}$ \\
\hline $\begin{array}{l}\text { Skodje et al., } \\
2018 \text { [58] }\end{array}$ & $\begin{array}{l}\text { Helduak } \\
\mathrm{n}=59 \\
\text { Pazienteak zoriz esleitu } \\
\text { ziren hiru taldetan, eta } \\
\text { taldeetako bakoitzak glu- } \\
\text { tendun barratxoa, frukta- } \\
\text { nodun barratxoa edo pla- } \\
\text { zebo-barratxoa jan zuen. } \\
\end{array}$ & 3 aste & $\begin{array}{l}\text { Fruktanoek GSEZa pairatzen } \\
\text { zituen pazienteetan sintomak } \\
\text { eragin zituzten. }\end{array}$ \\
\hline $\begin{array}{l}\text { Dieterich } \text { et al., } \\
\quad 2018 \text { [59] }\end{array}$ & $\begin{array}{l}\text { Helduak } \\
\text { FUD jarraitua } \\
\text { GSEZa }(n=19) \\
\text { Osasun-kontrolak }(n=10)\end{array}$ & 8 aste & $\begin{array}{l}\text { FODMAP urriko dietak, eta } \\
\text { batez ere gluten gabeko dietak, } \\
\text { paziente horietan sintoma kli- } \\
\text { nikoak eta psikologikoak ho- } \\
\text { betu zituen. }\end{array}$ \\
\hline $\begin{array}{l}\text { Zanini et al., } \\
2015 \text { [60] }\end{array}$ & $\begin{array}{l}\text { Helduak } \\
\text { GGDa }(\mathrm{n}=35)\end{array}$ & 5 aste & $\begin{array}{l}\text { Erronkak sintomen errepika- } \\
\text { pena sortzen zuen pazienteen } \\
\text { herenean: glutenarekiko senti- } \\
\text { kortasun ez-zeliakoa zuten pa- } \\
\text { zienteetan soilik. }\end{array}$ \\
\hline $\begin{array}{c}\text { Biesiekierski et al., } \\
2013 \text { [61] }\end{array}$ & $\begin{array}{l}\text { Hellduak } \\
\text { FUDa }(\mathrm{n}=37)\end{array}$ & 6 aste & $\begin{array}{l}\text { Ez zen glutenaren dosiarekiko } \\
\text { efektu espezifiko edo depen- } \\
\text { dienteen ebidentziarik aurkitu } \\
\text { FODMAP urriko dieta egi- } \\
\text { ten zuten eta gluten gabeko } \\
\text { GSEZa zuten pazienteetan. }\end{array}$ \\
\hline $\begin{array}{l}\text { Peters } \text { et al., } \\
2014 \text { [62] }\end{array}$ & $\begin{array}{l}\text { Helduak } \\
\text { FUDa }(\mathrm{n}=37)\end{array}$ & 8-17 hilabete & $\begin{array}{l}\text { GGDak dietak depresiora jo- } \\
\text { tzen zuten sentimentuak so- } \\
\text { rraraztera eraman zuen, baina } \\
\text { ez zuen beste erakusle batzue- } \\
\text { tan efekturik izan. Nahiz eta } \\
\text { urdail-hesteko sintomak edu- } \\
\text { kitzen jarraitu, hobea izan zen } \\
\text { GSEZa zuten pazienteetan glu- } \\
\text { ten gabeko dieta eramatea. }\end{array}$ \\
\hline
\end{tabular}

Laburdurak: GSEZ (glutenarekiko sentikortasun ez-zeliakoa), GGD (gluten gabeko dieta), FUD (FODMAP urriko dieta). 


\subsection{Esklerosi sistemikoa}

ESa beste erreumadun gaixotasunek baino heriotza-tasa altuagoa duen gaixotasun immunea da, eta gaixotasun arrarotzat jotzen da. Haren prebalentzia 8,2/10.000 da: antzekoak diren gaixotasunekin konparatuta, hala nola artritis erreumatoidearekin, nahiko baxua da. Gaixotasunaren sintomen garapenak eta ondorioek ziurgabetasun handia eragiten dute pazienteetan; izan ere, manifestazio klinikoak potentzialki hilgarriak edota bizi-kalitatea murrizteko adinakoak izan daitezke. ESaren lehengo zeinu klinikoak ezberdinak izan daitezke. Paziente askok azaleko gaixotasun inflamatorioak, atzamar handituak, inflamazio muskulueskeletikoa edo nekea aurkez ditzakete. Beste batzuek, ordea, organoetan oinarrituta dauden adierazpenak izaten dituzte, hala nola birika-fibrosia, birika-hipertentsio arteriala, giltzurrun-gutxiegitasuna edo/eta urdail-hesteetako konplikazioak [63, 64].

7. taula. FODMAP urriko dietak ES duten pazienteetan erakutsi dituen eraginak.

\begin{tabular}{c|l|c|c}
\hline Autoreak, urtea & $\begin{array}{c}\text { Laginaren tamaina } \\
\text { eta interbentzioaren } \\
\text { ezaugarriak }\end{array}$ & $\begin{array}{c}\text { Tratamenduaren } \\
\text { iraupena }\end{array}$ & \multicolumn{1}{c}{ Emaitza } \\
\hline $\begin{array}{c}\text { Marie } \text { et al., } \\
2015 \text { [65] }\end{array}$ & $\begin{array}{l}\text { Helduak } \\
\text { FUDa (n=80) }\end{array}$ & Hilabete 1 & $\begin{array}{l}\text { Sintoma gastrointestina- } \\
\text { len hobekuntza egon zen: } \\
\text { zehazki, goragalearen, go- } \\
\text { rakoaren, sabeleko minaren, } \\
\text { sabel-hantura, beherakoa } \\
\text { eta sabel-sentikortasunaren } \\
\text { hobekuntza. Idorrerian ez } \\
\text { zen aldaketarik ikusi. }\end{array}$ \\
\hline $\begin{array}{c}\text { Doerfler } \text { et al., } \\
2017 \text { [66] }\end{array}$ & $\begin{array}{l}\text { MNTIa (n=14) } \\
\text { FUDa sabel-hanturaren, } \\
\text { idorreriaren eta flatulen- } \\
\text { tzien tratamenduan era- } \\
\text { bili zen. }\end{array}$ & 6 aste & $\begin{array}{l}\text { Sintoma gastrointestinalen } \\
\text { murrizketan erabilgarria } \\
\text { izan zen FUD. }\end{array}$ \\
\hline
\end{tabular}

Laburdurak: FUD (FODMAP urriko dieta), MNTI (terapia mediko-nutrizional indibidualizatua).

FUDa eramateak urdail-hesteko sintomen murritea ekarri zuen emaitza gisa.

\subsection{Fribromialgia}

Fibromialgia min muskulueskeletiko orokorra sortzen duen patologia da. Fibromialgia duten pazienteek beste arazo somatiko-funtzional batzue- 
kin banatzen dituzte beren seinale klinikoak: mialgien arazoak, artralgiak, nekea eta loaren aztoratzeak. Espainiako Estatuan fibromialgiaren prebalentzia \% 2,4 ingurukoa da 20 urte baino gehiago duten norbanakoen artean. Emakumezkoetan askoz ere ohikoagoa da. Haren etiopatogenia ezezaguna da. Gaur egun, minaren erregulazioaren aztoratzea izango balitz bezala hartzen da kontuan [67-69].

8. taula. FODMAP urriko dietak fibromialgia duten pazienteetan erakutsi dituen eraginak.

\begin{tabular}{c|l|c|l}
\hline Autoreak, urtea & $\begin{array}{c}\text { Laginaren tamaina } \\
\text { eta interbentzioaren } \\
\text { ezaugarriak }\end{array}$ & $\begin{array}{c}\text { Tratamenduaren } \\
\text { iraupena }\end{array}$ & Emaitza \\
\hline $\begin{array}{c}\text { Marum } \text { et al., } \\
2017[70]\end{array}$ & FUDa $(\mathrm{n}=38)$ & 4 aste & $\begin{array}{l}\text { Nutrizionalki orekatua zen } \\
\text { FUDarekin sintomen larrita- } \\
\text { suna murriztu zen, hala nola } \\
\text { min somatiko, tentsio mus- } \\
\text { kular, loaren kalitate, antsie- } \\
\text { tate, depresio eta asteniaren } \\
\text { larritasuna. }\end{array}$ \\
\hline $\begin{array}{c}\text { Marum } \text { et al., } \\
2016[71]\end{array}$ & $\begin{array}{l}\text { Helduak } \\
\text { FUDa (n=38) }\end{array}$ & 4 aste & $\begin{array}{l}\text { FUDak urdail-hesteko sinto- } \\
\text { men murrizketa esanguratsua } \\
\text { ekarri zuen. }\end{array}$ \\
\hline
\end{tabular}

Laburdurak: FUD (FODMAP urriko dieta).

Lortu ziren ondorioek FUDa egitearen onurak adierazi zituzten.

\section{ONDORIOAK}

FODMAP urriko dieta erabilgarria eta eraginkorra da urdail-hesteko sintomak eragiten dituzten gaixotasunen maneiurako. Heste-narritakorraren sindromean, hesteetako gaixotasun inflamatorioan, zeliakian eta glutenarekiko sentikortasun ez-zeliakoan ager daitezkeen heste-sintomen murrizketarako eraginkorra dela erakutsi dute zenbait entsegu klinikok. Esklerosi sistemikoan eta fibromialgian ikerketa gutxiago egin badira ere, egun arte argitaratu diren lanek dieta erabilgarria izan daitekeela adierazi dute.

FODMAP urriko dietari jarraitzeak eguneroko dietan ohikoak diren zenbait elikagai murriztea dakar du, hala nola lekaleak, esnekiak, fruta eta barazki batzuk, eta murrizketa horrek, arretaz egiten ez bada, gabezia nutrizionalak pairatzera bultza dezake pertsona. Hori dela eta, FODMAP urriko dieta egiteko dietista-nutrizionisten kontrola ezinbestekoa da, pazientea 
hezi beharko baitu dietatik baztertzen dituen elikagai horiek zein beste elikagairekin ordezkatu behar dituen irakatsiz. Gainera, dietaren ezarpena pausoz pauso egin beharra dago, elikagai bakoitzarekiko tolerantzia aztertuz, beti ez baitira norbanako guztientzat elikagai berak baztertu behar. Dieta pertsonalizatua izango da, pertsonak ondo toleratzen duela frogatuko da, eta oreka nutrizionala bermatu beharko du. Horrez gain, pazientearen jarraipena egitea beharrezkoa izango da dietarekiko atxikimenduaren beherakada bat gerta ez dadin denborarekin.

Etorkizunera begira, dieta horren inguruan ikertzen jarraitu beharra dago. Egin diren entsegu klinikoek epe laburrean heste-gaixotasunetan efektu onuragarriak dituela erakutsi badute ere, beharrezkoa da epe luzera FODMAP urriko dietak zer-nolako eraginak izango dituen aztertzea. Horrez gain, hesteko sintomez aparte, hestez kanpoko sintometan ere onurarik duen ikustea interesgarria litzateke, edota beste gaixotasun batzuetan (heste-hanturarik gertatzen ez denetan) erabilgarria izan daitekeen edo ez ikertzea. Hori horrela izanik, eta gaur arteko emaitzak ikusita, aipatutako neurriekin ezarriz gero eta adherentzia mantenduz gero, argi dago gaixo askoren sintomatologia apaltzen duen eta ondorioz haien bizi-kalitatea ere hobetu dezakeen dieta baten aurrean gaudela. 

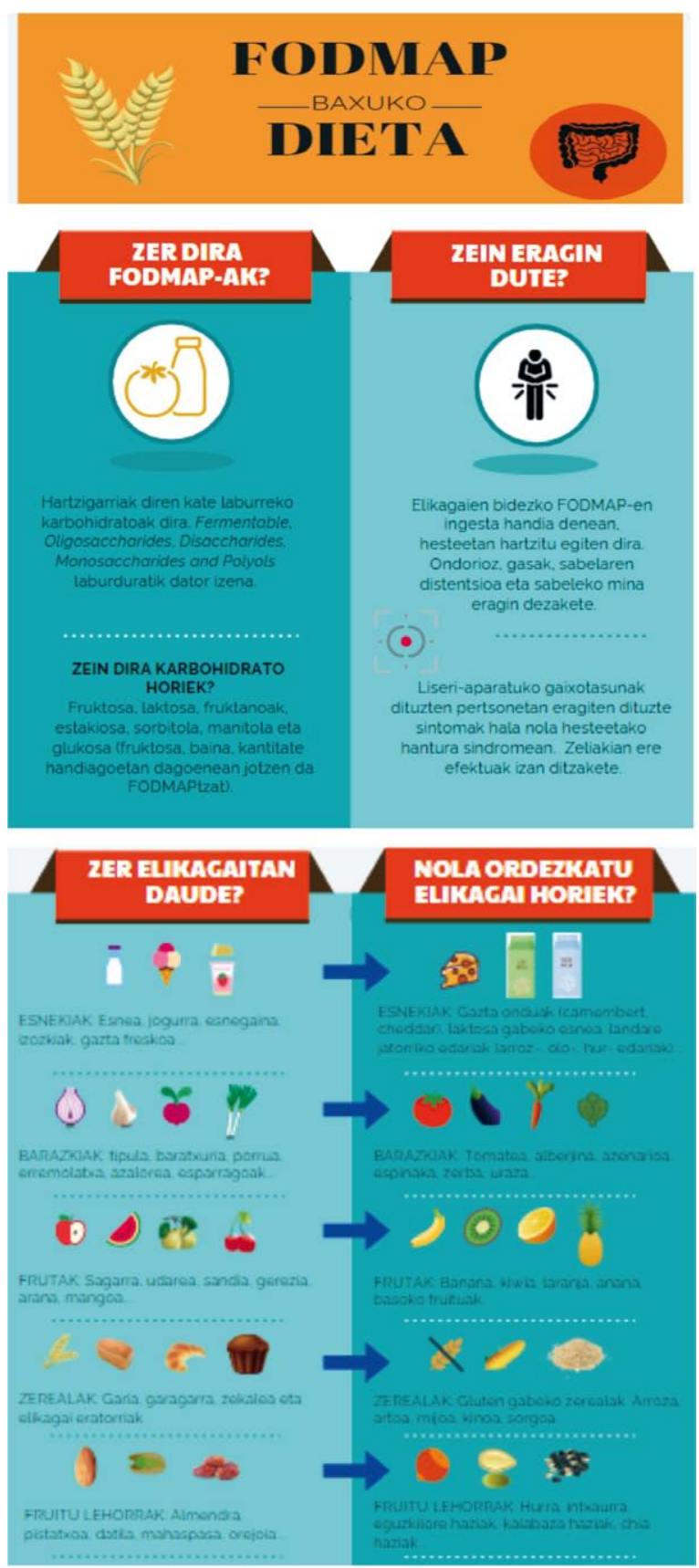

1. eranskina. FODMAP urriko dietari buruzko oinarrizko kontzeptuak azaltzen dituen infografia. 
G. Perez-Junkera, A. Lasa, J. Miranda, V. Navarro, E. Simón, I. Larretxi, O. Martinez, M. Bustamante, I. Txurruka, M. Vazquez-Polo

\begin{tabular}{|c|c|c|}
\hline & Egun bateko elikagaien zerrenda & Anoak \\
\hline Gosaria & $\begin{array}{l}\text { - Infusioa. } \\
\text { - Laranja bat. } \\
\text { - Gluten gabeko ogi integralezko } \\
\text { tostadak, tomate birrindu eta ur- } \\
\text { daiazpiko egosiarekin. }\end{array}$ & $\begin{array}{l}\text { - Infusioa: katilu bat. } \\
\text { - Laranja handi bat. } \\
\text { - Ogia: esku-ahurraren tamainako } \\
\text { bi zati. } \\
\text { - Tomate birrindua: hiru goilara- } \\
\text { kada. } \\
\text { - Urdaiazpiko egosia: bi xerra. }\end{array}$ \\
\hline Hamaiketakoa & - Anana. & - Hiru anana-xerra. \\
\hline Bazkaria & $\begin{array}{l}\text { - Arroza barazkiekin: azenarioa, } \\
\text { alberjina eta tomatea. } \\
\text { - Camembert gazta zati bat. } \\
\text { - Gluten gabeko ogi integral zati } \\
\text { bat. }\end{array}$ & $\begin{array}{l}\text { - Arroza (gordinik): kafe-katilu } \\
\text { bat. } \\
\text { - Bi azenario. } \\
\text { - Alberjina erdia. } \\
\text { - Tomate bat. } \\
\text { - Koilara bat oliba-olio. } \\
\text { - Hatz baten zabalera duen Ca- } \\
\text { membert gazta zati bat. } \\
\text { - Ogia: xerra ertain bat edo bi txiki. }\end{array}$ \\
\hline Askaria & $\begin{array}{l}\text { - Platano bat. } \\
\text { - Hurrak. }\end{array}$ & $\begin{array}{l}\text { - Platano ertain bat. } \\
\text { - Hurrak: eskutada txiki bat. }\end{array}$ \\
\hline Afaria & $\begin{array}{l}\text { - Uraza-, tomate-, pepino- eta ar- } \\
\text { to-entsalada. } \\
\text { - Legatza plantxan. } \\
\text { - Gluten gabeko ogi integrala. }\end{array}$ & $\begin{array}{l}\text { - Uraza: bi eskutada. } \\
\text { - Tomate bat. } \\
\text { - Pepino laurden bat. } \\
\text { - Artoa: kafe-katilu bat. } \\
\text { - Oliba-olioa: bi koilarakada. } \\
\text { - Ozpina: koilarakada bat. } \\
\text { - Legatza: xerra bat. } \\
\text { - Ogia: xerra ertain bat edo bi } \\
\text { txiki. }\end{array}$ \\
\hline $\begin{array}{l}\text { Nutrienteen } \\
\text { banaketa }\end{array}$ & \multicolumn{2}{|c|}{$\begin{array}{l}\text { Energia } \rightarrow 2.270 \mathrm{kcal} . \\
\text { Karbohidratoak } \rightarrow 293 \mathrm{~g} . \\
\text { Proteinak } \rightarrow 76,6 \mathrm{~g} . \\
\text { Lipidoak } \rightarrow 81,22 \mathrm{~g} .\end{array}$} \\
\hline
\end{tabular}

2. eranskina. FODMAP urriko den eguneko menu baten adibidea.

\section{BIBLIOGRAFIA}

[1] WIFFIN M., SMITH L., ANTONIO J., JOHNSTONE J., BEASLEY L., ROBERTS J. 2019. «Effect of a short-term low fermentable oligiosaccharide, disaccharide, monosaccharide and polyol (FODMAP) diet on exerciserelated gastrointestinal symptoms». Journal of the International Society of Sports Nutrition. 16. 
[2] BELlini M., TONARELli S., NAGY GA., PANCETTI A., COSTA F, RICCHIUTI A. et al. 2020. «Low FODMAP Diet: Evidence, Doubts, and Hopes». Nutrients. 12.

[3] GIBSON PR., SHEPHERD SJ. 2010. «Evidence-based dietary management of functional gastrointestinal symptoms: The FODMAP approach». Journal of Gastroenterology and Hepatology. 25, 252-258.

[4] HALMOS EP., GIBSON PR. 2019. "Controversies and reality of the FODMAP diet for patients with irritable bowel syndrome». Journal of Gastroenterology and Hepatology.

[5] TUCK C., BARRETT J. 2017. «Re-challenging FODMAPs: the low FODMAP diet phase two». Journal of Gastroenterology and Hepatology. 32, 11-15.

[6] RONCORONI L., BASCUÑÁN KA., DONEDA L., SCRICCIOLO A., LOMBARDO V., BRANCHI F. et al. 2018. «A Low FODMAP GlutenFree Diet Improves Functional Gastrointestinal Disorders and Overall Mental Health of Celiac Disease Patients: A Randomized Controlled Trial». Nutrients. 10, 1023.

[7] CANICOBA M., NASTASI V. 2016. «La dieta reducida en FODMAP: ventajas y controversias». Nutrición Clínica en Medicina. 10, 20-39.

[8] GIBSON PR., SHEPHERD SJ. 2005. «Personal view: food for thought western lifestyle and susceptibility to Crohn's disease. The FODMAP hypothesis». Alimentary Pharmacology \& Therapeutics. 21, 1399-1409.

[9] VAKIL N. 2018. «Dietary Fermentable Oligosaccharides, Disaccharides, Monosaccharides, and Polyols (FODMAPs) and Gastrointestinal Disease». Nutrition in Clinical Practice. 33, 468-475.

10. HELFRICH K. The Pipetten Blog. The Science Writing and Communication Club (SWAC). University of North Carolina.

[11] MUIR JG., SHEPHERD SJ., ROSELLA O., ROSE R., BARRETT JS., GIBSON PR. 2007. «Fructan and Free Fructose Content of Common Australian Vegetables and Fruit». Journal of Agricultural and Food Chemistry. $\mathbf{5 5}, 6619-6627$.

[12] MUIR JG., ROSE R., ROSELLA O., LIELS K., BARRETT JS., SHEPHERD SJ. et al. 2009. «Measurement of Short-Chain Carbohydrates in Common Australian Vegetables and Fruits by High-Performance Liquid Chromatography (HPLC)». Journal of Agricultural and Food Chemistry. 57, 554-565.

[13] ONG DK., MITCHELL SB., BARRETT JS., SHEPHERD SJ., IRVING PM., BIESIEKIERSKI JR. et al. 2010. «Manipulation of dietary short chain carbohydrates alters the pattern of gas production and genesis of symptoms in irritable bowel syndrome». Journal of Gastroenterology and Hepatology. 25, 1366-1373.

[14] VARNEY J., BARRETT J., SCARLATA K., CATSOS P., GIBSON PR., MUIR JG. 2017. «FODMAPs: food composition, defining cutoff values and 
G. Perez-Junkera, A. Lasa, J. Miranda, V. Navarro, E. Simón, I. Larretxi, O. Martinez, M. Bustamante, I. Txurruka, M. Vazquez-Polo

international application». Journal of Gastroenterology and Hepatology. 32, 53-61.

[15] BARRETT JS. 2017. «How to institute the low-FODMAP diet». Journal of Gastroenterology and Hepatology. 32, 8-10.

[16] MOLINA-INFANTE J., SERRA J., FERNANDEZ-BAÑARES F., MEARIN F. 2016. «The low-FODMAP diet for irritable bowel syndrome: Lights and shadows». Gastroenterología y Hepatología. 39, 55-65.

[17] SIMON MAGRO E., RODRÍGUEZ RIVERA, B. 2007. «Giza Nutrizioaren eta Dietetikaren Oinarriak». Elhuyar Edizioak.

[18] HARVIE RM., CHISHOLM AW., BISANZ JE., BURTON JP., HERBISON P., SCHULTZ K. et al. 2017. «Long-term irritable bowel syndrome symptom control with reintroduction of selected FODMAPs». World Journal of Gastroenterology. 23, 4632-4643.

[19] STAUDACHER HM., LOMER MCE., ANDERSON JL., BARRETT JS., MUIR JG., IRVING PM. et al. 2012. «Fermentable Carbohydrate Restriction Reduces Luminal Bifidobacteria and Gastrointestinal Symptoms in Patients with Irritable Bowel Syndrome». The Journal of Nutrition. 142, 15101518.

[20]. HALMOS EP., CHRISTOPHERSEN CT., BIRD AR., SHEPHERD SJ., GIBSON PR., MUIR JG. 2015. «Diets that differ in their FODMAP content alter the colonic luminal microenvironment» Gut. 64, 93-100.

[21] MARI A., HOSADURG D., MARTIN L., ZARATE-LOPEZ N., PASSANANTI V., EMMANUEL A. 2019. «Adherence with a low-FODMAP diet in irritable bowel syndrome: are eating disorders the missing link?» European Journal of Gastroenterology \& Hepatology. 31, 178-182.

[22] O'KEEFFE M., JANSEN C., MARTIN L., WILLIAMS M., SEAMARK L., STAUDACHER HM. et al. 2018. "Long-term impact of the low-FODMAP diet on gastrointestinal symptoms, dietary intake, patient acceptability, and healthcare utilization in irritable bowel syndrome». Neurogastroenterology \& Motility. 30, 13154.

[23] DE ROEST RH., DOBBS BR., CHAPMAN BA., BATMAN B., O'BRIEN LA., LEEPER JA. et al. 2013. «The low FODMAP diet improves gastrointestinal symptoms in patients with irritable bowel syndrome: a prospective study». International Journal of Clinical Practice. 67, 895-903.

[24] MARSH A., ESLICK EM., ESLICK GD. 2016. «Does a diet low in FODMAPs reduce symptoms associated with functional gastrointestinal disorders? A comprehensive systematic review and meta-analysis». European Journal of Nutrition. 55, 897-906.

[25] MITCHELL H., PORTER J., GIBSON PR., BARRETT J., GARG M. 2019. «Review article: implementation of a diet low in FODMAPs for patients with irritable bowel syndrome-directions for future research». Alimentary Pharmacology \& Therapeutics. 49, 124-139.

[26] VAN DER WAAIJ LA., JANNEKE S. 2014. «FODMAP-beperkt dieet bij prikkelbaredarmsyndroom». Ned Tijdschr Geneeskd. 158, 1-6. 
[27] LOMER MCE. 2015. «Review article: the aetiology, diagnosis, mechanisms and clinical evidence for food intolerance». Alimentary Pharmacology \& Therapeutics. 41, 262-275.

[28]. Monash University. Starting The FODMAP Diet Victoria, Australia. Eskuragarri: https://www.monashfodmap.com/ibs-central/i-have-ibs/starting-thelow-fodmap-diet/.

[29] WHELAN K., MARTIN LD., STAUDACHER HM., LOMER MCE. 2018. «The low FODMAP diet in the management of irritable bowel syndrome: an evidence-based review of FODMAP restriction, reintroduction and personalisation in clinical practice». Journal of Human Nutrition and Dietetics. 31, 239-55.

[30] MCINTOSH K., REED DE., SCHNEIDER T., DANG F., KESHTELI AH., DE PALMA G. et al. 2017. «FODMAPs alter symptoms and the metabolome of patients with IBS: a randomised controlled trial». Gut. 66, 12411251 .

[31] BÖHN L., STÖRSRUD S., LILJEBO T., COLLIN L., LINDFORS P., TÖRNBLOM H. et al. 2015. «Diet Low in FODMAPs Reduces Symptoms of Irritable Bowel Syndrome as Well as Traditional Dietary Advice: A Randomized Controlled Trial». Gastroenterology. 149, 1399-1407.

[32] CHUMPITAZI BP., COPE JL., HOLLISTER EB., TSAI CM., MCMEANS AR., LUNA RA. et al. 2015. «Randomised clinical trial: gut microbiome biomarkers are associated with clinical response to a low FODMAP diet in children with the irritable bowel syndrome». Alimentary Pharmacology \& Therapeutics. 42, 418-427.

[33] ESWARAN SL., CHEY WD., HAN-MARKEY T., BALL S., JACKSON K. 2016. «A Randomized Controlled Trial Comparing the Low FODMAP Diet vs. Modified NICE Guidelines in US Adults with IBS-D». The American Journal of Gastroenterology. 111, 1824-1832.

[34] LAATIKAINEN R., KOSKENPATO J., HONGISTO SM., LOPONEN J., POUSSA T., HILLILÄ M. et al. 2016. «Randomised clinical trial: LowFODMAP rye bread vs. regular rye bread to relieve the symptoms of irritable bowel syndrome». Alimentary Pharmacology \& Therapeutics. 44.

[35] STAUDACHER HM., LOMER MCE., FARQUHARSON FM., LOUIS P., FAVA F., FRANCIOSI E. et al. 2017. «A Diet Low in FODMAPs Reduces Symptoms in Patients With Irritable Bowel Syndrome and A Probiotic Restores Bifidobacterium Species: A Randomized Controlled Trial». Gastroenterology. 153, 936-947.

[36] HUSTOFT TN., HAUSKEN T., YSTAD SO., VALEUR J., BROKSTAD K., HATLEBAKK JG. et al. 2017. «Effects of varying dietary content of fermentable short-chain carbohydrates on symptoms, fecal microenvironment, and cytokine profiles in patients with irritable bowel syndrome». Neurogastroenterology and Motility. 29, 10.

[37] PETERS SL., MUIR JG., GIBSON PR. 2015. «Review article: gut-directed hypnotherapy in the management of irritable bowel syndrome and inflamma- 
G. Perez-Junkera, A. Lasa, J. Miranda, V. Navarro, E. Simón, I. Larretxi, O. Martinez, M. Bustamante, I. Txurruka, M. Vazquez-Polo

tory bowel disease». Alimentary Pharmacology \& Therapeutics. 41, 11041115.

[38] PETERS SL., YAO CK., PHILPOTT H., YELLAND GW., MUIR JG., GIBSON PR. 2016. «Randomised clinical trial: the efficacy of gut-directed hypnotherapy is similar to that of the low FODMAP diet for the treatment of irritable bowel syndrome». Alimentary Pharmacology \& Therapeutics. 44, 447-459.

[39] SCHUMANN D., LANGHORST J., DOBOS G., CRAMER H. 2018. «Randomised clinical trial: yoga vs a low-FODMAP diet in patients with irritable bowel syndrome». Alimentary Pharmacology \& Therapeutics. 47, 203-211.

[40] MAAGAARD L., ANKERSEN DV., VÉGH Z., BURISCH J., JENSEN L., PEDERSEN N. et al. 2016. «Follow-up of patients with functional bowel symptoms treated with a low FODMAP diet». World Journal of Gastroenterology. 22, 4009-4019.

[41] WEYNANTS A., GOOSSENS L., GENETELLO M., DE LOOZE D., VAN WINCKEL M. 2020. «The long-term effect and adherence of a low fermentable oligosaccharides disaccharides monosaccharides and polyols (FODMAP) diet in patients with irritable bowel syndrome». Journal of $\mathrm{Hu}$ man Nutrition and Dietetics. 33, 159-169.

[42] WEHKAMP J., GÖTZ M., HERRLINGER K., STEURER W., STANGE EF., STANGE EF. 2016. «Inflammatory Bowel Disease». Deutsches Arzteblatt international. 113, 72-82.

[43] ZHANG Y-Z., LI Y-Y. 2014. «Inflammatory bowel disease: pathogenesis». World Journal of Gastroenterology. 20, 91-99.

[44] COX SR., PRINCE AC., MYERS CE., IRVING PM., LINDSAY JO., LOMER MC. et al. 2017. «Fermentable Carbohydrates [FODMAPs] Exacerbate Functional Gastrointestinal Symptoms in Patients With Inflammatory Bowel Disease: A Randomised, Double-blind, Placebo-controlled, Crossover, Re-challenge Trial». Journal of Crohn's and Colitis. 11, 1420-1429.

[45] GAJENDRAN M., LOGANATHAN P., CATINELLA AP., HASHASH JG. 2018. «A comprehensive review and update on Crohn's disease». Disease-aMonth. 64, 20-57.

[46] PRINCE AC., MYERS CE., JOYCE T., IRVING P., LOMER M., WHELAN K. 2016. «Fermentable Carbohydrate Restriction (Low FODMAP Diet) in Clinical Practice Improves Functional Gastrointestinal Symptoms in Patients with Inflammatory Bowel Disease». Inflammatory Bowel Diseases. 22, 1129-1136.

[47]. OSAKIDETZA. 2018. Enfermedad Inflamatoria Intestinal. INFAC. 26, 10.

[48] HALMOS EP., CHRISTOPHERSEN CT., BIRD AR., SHEPHERD SJ., MUIR JG., GIBSON PR. 2016. «Consistent Prebiotic Effect on Gut Microbiota With Altered FODMAP Intake in Patients with Crohn's Disease: A Randomised, Controlled Cross-Over Trial of Well-Defined Diets». Clinical and Translational Gastroenterology. 7, 164. 
[49] BODINI G., ZANELLA C., CRESPI M., LO PUMO S., DEMARZO MG., SAVARINO E. et al. 2019. «A randomized, 6-wk trial of a low FODMAP diet in patients with inflammatory bowel disease». Nutrition. 67-68.

[50] PEDERSEN N., ANKERSEN DV., FELDING M., WACHMANN H., VÉGH Z., MOLZEN L. et al. 2017. «Low-FODMAP diet reduces irritable bowel symptoms in patients with inflammatory bowel disease». World Journal of Gastroenterology. 23, 3356-3366.

[51] LEFFLER DA., GREEN PHR., FASANO A. 2015. «Extraintestinal manifestations of coeliac disease». Nature Reviews Gastroenterology \& Hepatology. 12, 561-571.

[52] LUDVIGSSON JF., BAI JC., BIAGI F., CARD TR., CIACCI C., CICLITIRA PJ. et al. 2014. «Diagnosis and management of adult coeliac disease: guidelines from the British Society of Gastroenterology». Gut. 63, 1210.

[53] LEBWOHL B., SANDERS DS., GREEN PHR. 2018. «Coeliac disease». The Lancet. 391, 70-81.

[54] VAQUERO L., ÁLVAREZ-CUENLLAS B., RODRÍGUEZ-MARTÍN L., APARICIO M., JORQUERA F., OLCOZ JL. et al. 2015. «Revisión de las patologías relacionadas con la ingesta de gluten». Nutrición Hospitalaria. 31, 2359-2371.

[55] CHOUNG RS., LARSON SA., KHALEGHI S., RUBIO-TAPIA A., OVSYANNIKOVA IG., KING KS. et al. 2017. «Prevalence and Morbidity of Undiagnosed Celiac Disease From a Community-Based Study». Gastroenterology. 152, 830-839.

[56] BARBARO MR., CREMON C., STANGHELLINI V., BARBARA G. 2018. «Recent advances in understanding non-celiac gluten sensitivity». Research. 7, 1631 .

[57] TESTA A., IMPERATORE N., RISPO A., REA M., TORTORA R., NARDONE OM. et al. 2018. «Beyond Irritable Bowel Syndrome: The Efficacy of the Low Fodmap Diet for Improving Symptoms in Inflammatory Bowel Diseases and Celiac Disease». Digestive Diseases. 36, 271-280.

[58] SKODJE GI., SARNA VK., MINELLE IH., ROLFSEN KL., MUIR JG., GIBSON PR. et al. 2018. «Fructan, Rather Than Gluten, Induces Symptoms in Patients With Self-Reported Non-Celiac Gluten Sensitivity». Gastroenterology. 154, 529-539.

[59] DIETERICH W., SCHUPPAN D., SCHINK M., SCHWAPPACHER R., WIRTZ S., AGAIMY A. et al. 2019. «Influence of low FODMAP and gluten-free diets on disease activity and intestinal microbiota in patients with non-celiac gluten sensitivity». Clinical Nutrition. 38, 697-707.

[60] ZANINI B., BASCHÈ R., FERRARESI A., RICCI C., LANZAROTTO F., MARULLO M. et al. 2015. «Randomised clinical study: gluten challenge induces symptom recurrence in only a minority of patients who meet clinical criteria for non-coeliac gluten sensitivity». Alimentary Pharmacology \& Therapeutics. 42, 968-976. 
G. Perez-Junkera, A. Lasa, J. Miranda, V. Navarro, E. Simón, I. Larretxi, O. Martinez, M. Bustamante, I. Txurruka, M. Vazquez-Polo

[61] BIESIEKIERSKI JR., PETERS SL., NEWNHAM ED., ROSELLA O., MUIR JG., GIBSON PR. 2013. «No Effects of Gluten in Patients With SelfReported Non-Celiac Gluten Sensitivity After Dietary Reduction of Fermentable, Poorly Absorbed, Short-Chain Carbohydrates». Gastroenterology. 145, 320-328.

[62] PETERS SL., BIESIEKIERSKI JR., YELLAND GW., MUIR JG., GIBSON PR. 2014. «Randomised clinical trial: gluten may cause depression in subjects with non-coeliac gluten sensitivity - an exploratory clinical study». Alimentary Pharmacology \& Therapeutics. 39, 1104-1112.

[63] DENTON CP., KHANNA D. 2017. «Systemic sclerosis». The Lancet. 390, 1685-1699.

[64] HUGHES M., HERRICK AL. 2019. «Systemic sclerosis». British Journal of Hospital Medicine. 80, 530-536.

[65] MARIE I., LEROI A-M., GOURCEROL G., LEVESQUE H., MÉNARD J-F., DUCROTTE P. 2015. «Fructose Malabsorption in Systemic Sclerosis». Medicine. 94, 1601.

[66] DOERFLER B., ALLEN TS., SOUTHWOOD C., BRENNER D., HIRANO I., SHEEAN P. 2017. «Medical Nutrition Therapy for Patients With Advanced Systemic Sclerosis (MNT PASS): A Pilot Intervention Study». Journal of Parenteral and Enteral Nutrition. 41, 678-684.

[67] BORCHERS A., GERSHWIN M. 2015. «Fibromyalgia: A Critical and Comprehensive Review». Clinical Reviews in Allergy \& Immunology. 49, 100-151.

[68] BRANCO JC., BANNWARTH B., FAILDE I., ABELLO CARBONELL J., BLOTMAN F., SPAETH M. et al. 2010. «Prevalence of Fibromyalgia: A Survey in Five European Countries». Seminars in Arthritis and Rheumatism. 39, 448-453.

[69] SLUKA KA., CLAUW DJ. 2016. «Neurobiology of fibromyalgia and chronic widespread pain». Neuroscience. 338, 114-129.

[70] MARUM AP., MOREIRA C., TOMAS-CARUS P., SARAIVA F., GUERREIRO CS. 2017. «A low fermentable oligo-di-mono-saccharides and polyols (FODMAP) diet is a balanced therapy for fibromyalgia with nutritional and symptomatic benefits». Nutricion Hospitalaria. 34, 667-674.

[71] MARUM ANA P., MOREIRA C., SARAIVA F., TOMAS-CARUS P., SOUSA-GUERREIRO C. 2016. «A low fermentable oligo-di-mono saccharides and polyols (FODMAP) diet reduced pain and improve daily life in fibromyalgia patients». Scandinavian Journal of Pain. 13, 166-172. 